\title{
Recurrent intraosseous ganglia in the proximal tibia following anterior cruciate ligament reconstruction using patella tendon bone autograft with a titanium interference screw: A case report
}

\author{
Aysha Rajeev, James Henry, Nanjappa Kashyap
}

\begin{abstract}
Introduction: Intraosseous ganglia are benign cystic lesions and often multiloculated lesions located in the subchondral bone. These lesions are often asymptomatic but in cases located close to neurovascular structures or articular surfaces, they can be symptomatic, causing pain, neurologic dysfunction or articular fractures. We report a rare case of recurrent intraosseous ganglion following an anterior cruciate ligament (ACL) reconstruction in the proximal tibia. The ganglion developed after ten years of ACL reconstruction using patella tendon bone autograft fixed with a titanium interference screw. Initially the swelling mimicked the clinical and radiological features of a bone tumor. Case Report: A 40-year-old Caucasian male underwent ACL reconstruction using patella tendon bone graft and a titanium interference screw fixation in the tibia. After ten years of surgery he noticed a lump in the proximal tibia at the site of tibial screw. The radiological features were unremarkable. He had excision of the swelling along with screw removal. The swelling recurred again within six months. The lump was excised again and tibial tunnel bone
\end{abstract}

Aysha Rajeev ${ }^{1}$, James Henry ${ }^{2}$, Nanjappa Kashyap ${ }^{3}$

Affiliations: ${ }^{1}$ Associate Specialist, Dept. of Orthopaedics and Trauma, Queen Elizabeth Hospital, Gateshead, UK; ${ }^{2}$ Consultant, Dept. of Histo Pathology, Queen Elizabeth Hospital, Gateshead, UK; ${ }^{3}$ Consultant, Dept. of Orthopaedics and Trauma, Queen Elizabeth Hospital, Gateshead,UK. Corresponding Author: Aysha Rajeev, 25, Fatfield Park, Washington. Tyne And Wear, UK; Contact No: 00441914190315; Email: asrajeev18@gmail.com

Received: 31 October 2012

Accepted: 04 February 2013

Published: 01 September 2013 grafted. After 4 weeks the lump reappeared, magnetic resonance imaging scan showed a large cystic lesion in the proximal tibia. After taking the advice from the oncologist, the lesion was curetted and bone grafted. The cyst went on to heal completely in six months time. Conclusion: The occurrence of intraosseous ganglion with absorbable interference screw has been reported. In our case report the intraosseous ganglion formed after using a titanium interference screw which has not been reported previously. It is also unique in the sense that the swelling recurred thrice and mimicked characteristics of a bone tumor.

Keywords: Recurrent, Intraosseous, Titanium interference screw, Mimic bone tumour

$* * * * * * * * *$

Rajeev A, Henry J, Kashyap N. Recurrent intraosseous ganglia in the proximal tibia following anterior cruciate ligament reconstruction using patella tendon bone autograft with a titanium interference screw: A case report. International Journal of Case Reports and Images 2013;4(9):502-506.

$$
* * * * * * * * *
$$

doi:10.5348/ijcri-2013-09-366-CR-10

\section{INTRODUCTION}

The occurrence of intraosseous ganglions is not that common. Ganglions are commonly soft tissue benign tumors usually arise in close proximity to joints, tendon or its sheaths [1]. The intraosseous penetration of a periosteal ganglion-like structures with subsequent formation of a bone cyst has been described in the past 
[2]. Intraosseous ganglia occur subchondrally, with or without an intact articular cartilage [3]. Sometimes the lesions occur in the metaphysis with connections to the joint surface or to the adjacent ligamentous structures [4].

Various theories have been proposed as to the pathogenesis of these ganglions. These include degeneration of connective tissue and migration of synovial fluid from an adjacent joint [1]. The possibility of acute or chronic trauma as one of the causative factors in these type of ganglions have also been postulated in a small percentage of patients [5]. The presence of serosanguinous mucin in the aspirate of these ganglions support this theory. Trauma sometimes cause to myxoid or mucinous degeneration which in turn leads to the pathogenesis of the ganglion [6].

In this case report, the patient developed an intraosseous ganglion almost ten years following an anterior cruciate ligament (ACL) reconstruction using patella tendon bone graft. The ganglion was located in the site of the tibial titanium interference screw. We are reporting this case as a unique and rare cause of recurrent and resistant intraosseous ganglion which has never been cited in English literature.

\section{CASE REPORT}

A 40-year-old Caucasian male underwent ACL reconstruction of the right knee using patella-tendon bone graft in 1999. He was doing extremely well for 10 years. In 2009 while playing football he had a knock on the medial aspect of the tibia. He noticed a lump just below the medial side of the knee which became very painful. There were no symptoms of instability. He had pain radiating from the lump on to the front of the upper leg. He was active and continued with his job.

On examination, there was no deformity of the knee. There was lump on the medial aspect of the tibial tuberosity, at the site of the tibial screw insertion for ACL reconstruction. The swelling was about $4 \times 4 \mathrm{~cm}$, tender with on redness or signs of inflammation. The movements were full range and tests for instability were negative. There was no distal neurovascular deficit. The radiological examination of the knee showed early degenerative changes in all three compartments. The position of the tibial screw was satisfactory with no bony changes (Figure 1). He was listed for planned procedure to take the tibial screw out. At the time of surgery the surgeon noticed a large soft tissue ganglion over the screw head. This was excised en-bloc and screw removed. The patient was reviewed back in the clinic two weeks following the surgery. He had mild ooze from the wound and swab was send for culture and sensitivity. The patient was again reviewed back in the clinic after one week which showed a jelly like material oozing from the wound but the culture reports were negative. He continued to receive wound dressings over the next few weeks and the wound healed satisfactorily, and the lump reappeared.
The patient returned six months after the operation with increased pain and swelling in the medial aspect of the knee. Physical examination showed a tender lump about $5 \times 5 \mathrm{~cm}$ under the scar tissue. A decision was taken to excise the lump and bone graft the tibial tunnel. The scar was opened and the ganglion was excised and the tibial tunnel was grafted using freeze dried bone. Postoperatively the patient did well, the wound healed satisfactorily and the swelling disappeared.

The patient was then re-referred within four weeks by his general practioner with increasing pain and swelling at the operative site. On examination, the wound has healed well and there was only a small tender lump palpable about $2 \times 2 \mathrm{~cm}$. The X-ray revealed that graft is incorporating well (Figure 2). In view of the continuing symptoms he was referred for an MRI scan urgently. The scan revealed a large cystic lesion in the proximal tibia (Figure 3). The patient was referred to the regional tumor unit for expert opinion. The tumor surgeon reported that the patient had got a recurrent intraosseous ganglion. A decision was taken to curette and bone graft lesion. The patient underwent excision of the ganglion and bone grafting using fresh frozen femoral head and tissue samples were send for histopathology (Figure 4). The patient was followed-up second week, sixth week and sixth month following the operation. The histopathology showed mature bone with fibro-collagenous tissue showing myxoid change and chronic inflammation. The myxoid material extends into bone suggesting an intraosseous ganglion. The cyst healed (Figure 5) and patient regained full knee movements. He was discharged from the outpatient clinic after 1 year.

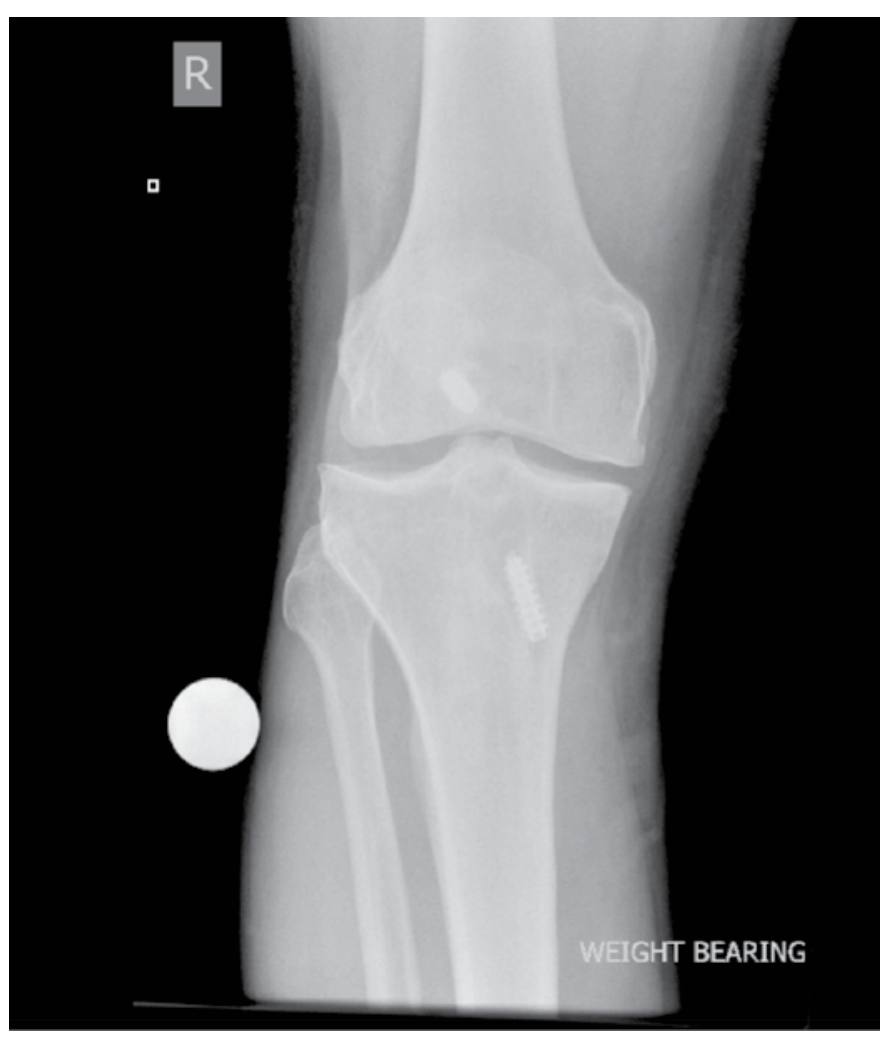

Figure 1: The radiograph showing tibial screw in-situ with no bony changes. 


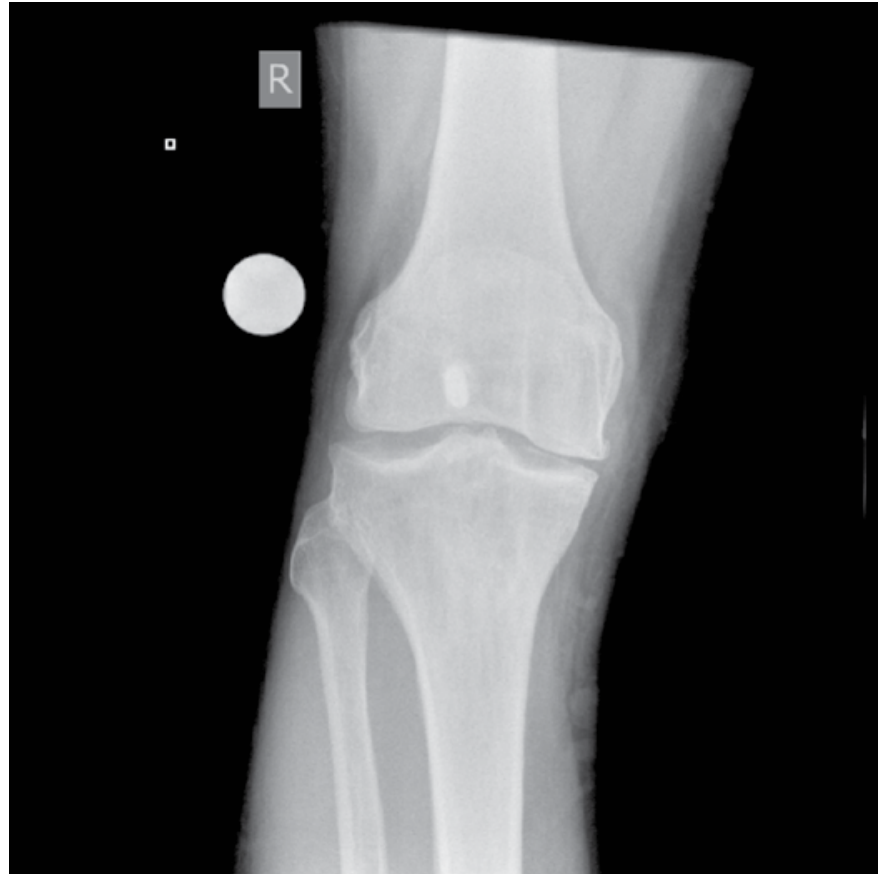

Figure 2: X-ray showing the graph incorporating well after the first surgery.

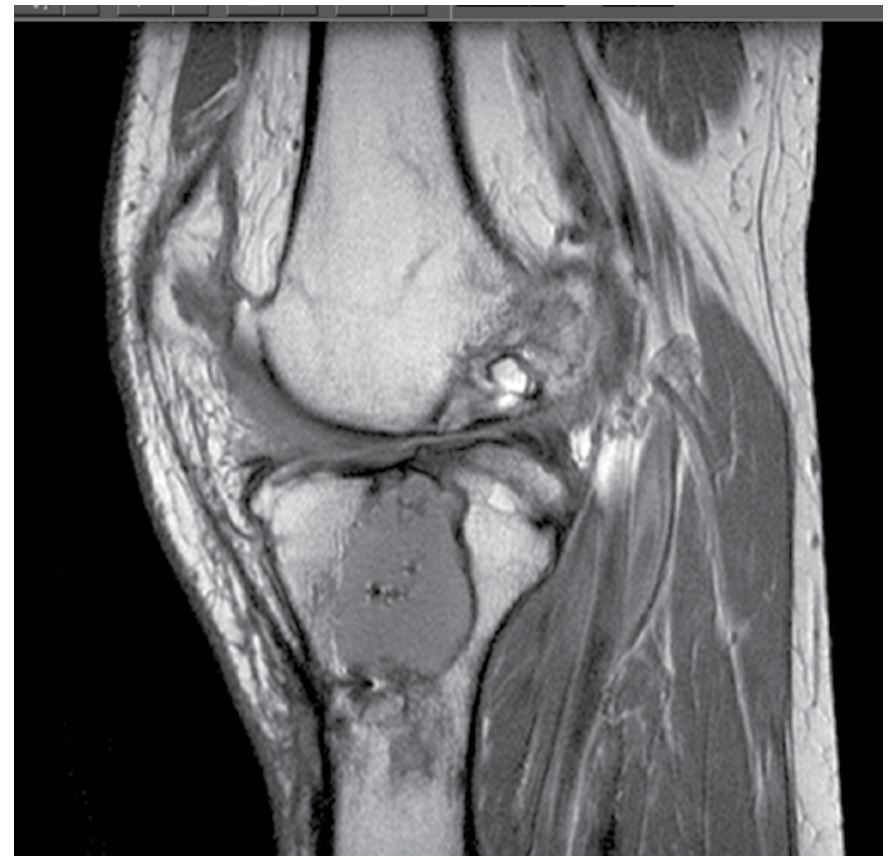

Figure 3: Magnetic resonance imaging scan showing a large cystic lesion in the proximal tibia.

\section{DISCUSSION}

The diagnosis of intraosseous ganglion should be considered in the absence of previous inflammatory and degenerative joint lesions. Most of these cases occur between the ages of 14-73. There are basically two types of intraosseous ganglia-one is idiopathic and the other one caused by penetration of an extraosseous ganglion into the underlying bone [1]. The juxta-articular, intraosseous ganglion reported in our case belongs to the second type,

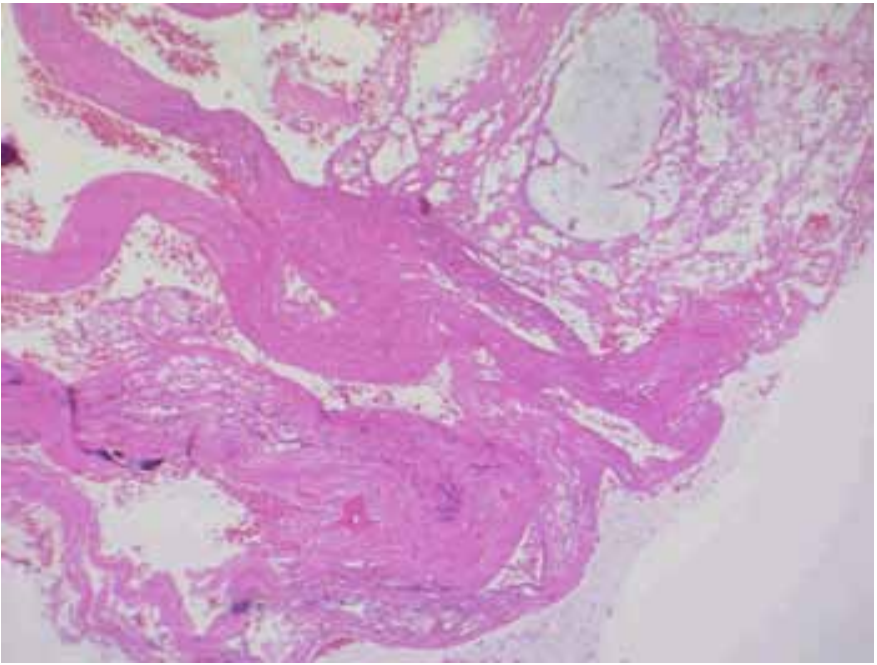

Figure 4: Histopathology showing bony tissue mixed with myxoid fibrous tissue consistent with an intraosseous ganglion.

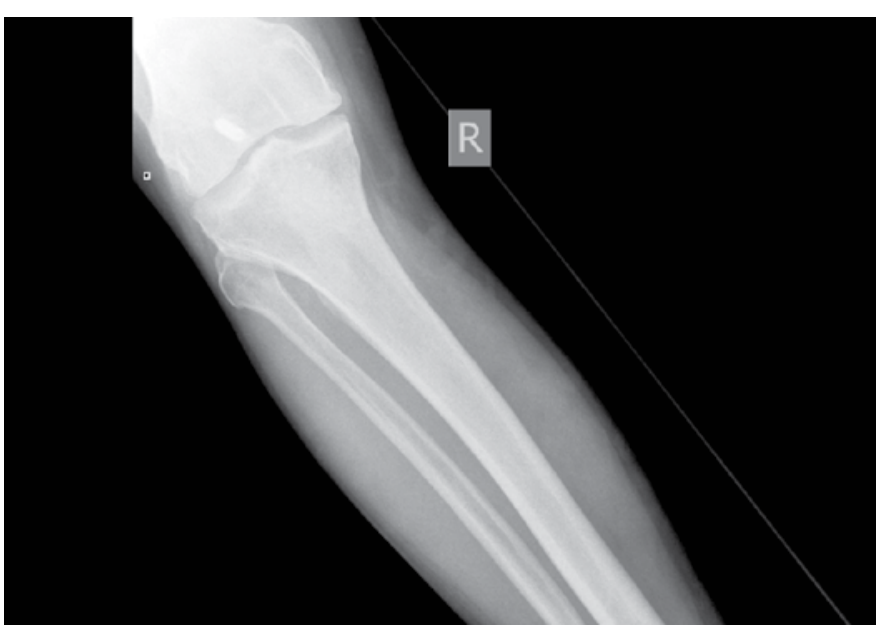

Figure 5: Final radiograph showing the cyst well healed after curettage and bone grafting.

in which a soft tissue ganglion developed first and later penetrated into the underlying proximal tibia.

There are several theories proposed about the pathogenesis of intraosseous ganglions. The best possible theory would be a combination of intramedullary metaplasia followed by fibroblast proliferation. The fibroblasts secretes both hyaluronic acid and mucin which tend to accumulate and cause pressure necrosis. This leads to intramedullary trabecular degeneration and the formation of intraosseous cyst formation [3].

Most of the intraosseous ganglia lie subchondrally, with a normal articular cartilage and rarely communicate with joint or tendon sheath. The intact cyst often appears relatively smooth, round to oval shaped with an ochreyellow color similar to a soft tissue ganglia, containing a thick gelatinous material. Microscopically, the walls are lined by poorly vascularized fibrous tissue and the cavity with flattened connective tissue cells which sometimes 
resemble synovial histiocytes. The secretion is high in hyaluronic acid and other mucopolysaccharides along with glucosamine, albumin and globulin.

The radiological features of an intraosseous ganglion include a scalloped cortical defect with a sclerotic margin. They appear thick and well defined which indicates a slow growing lesion [7]. These lesions very rarely shows calcification [8].

An MRI scan shows features similar to degenerative cysts with the overlying joint showing a normal articulation. The intraosseous ganglion may or may not communicate with the joint. The lesions show a fluid like appearance with low intensity on T1-weighted images, moderately low intensity on proton density weighted images and high homogenous intensity on T2-images.

The differential diagnosis of intraosseous ganglion is mainly giant cell tumor and chondroblastoma. Giant cell tumors are locally aggressive composed of giant cells, connective tissue and stromal cells. They usually occur between 3 rd and 4 th decade and predominantly epiphyseal location after growth plate closure. Chondroblastoma are commonly seen before skeletal maturity. Radiologically, they tend to be well defined lucent lesions with a sclerotic margins with calcification seen in $50 \%$ of cases.

The formation of cyst in the tibial tunnel after the use of an absorbable interference screw have been described [9]. Majority of the interference screws being used now-adays are made of biodegradable material. The polylactide material causes hydrolysis and phaocytois [10]. This causes inflammatory foreign-body reactions responsible for as osteolytic reaction around the screw. Malhan et al. postulated that the gradual accumulation of breakdown products in a closed tibial tunnel ultimately lead to a cyst formation [11]. In our case report the interference screw was made of titanium.

The occurrence of pretibial cyst formation in the proximal tibia after ACL reconstruction has been reported with patella tendon autograft with the use of bioabsorbable interference screws $[12,13]$. The actual mechanism by which these cyst forms has not been established. A mismatch of graft tunnel diameter, eccentric tibial tunnel, bone necrosis may slow down the incorporation of the graft into the tibia. This may lead to a water-channel between the knee joint and the proximal tibia there by leading to the formation of a cyst [14]. There has been no reports of any cyst formation using a titanium interference screw.

\section{CONCLUSION}

This is a rare case of intraosseous ganglion following anterior cruciate ligament reconstruction. The intraarticular communication after anterior cruciate ligament reconstruction of proximal tibia thereby causing the synovial fluid to flow to the proximal tibia under pressure may have attributed to the development of intraosseous ganglion. The clinician should be aware that it can mimic a bone tumor. The pathologic lesion can be successfully treated with curettage and bone grafting.

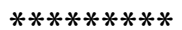

\section{Author Contributions}

Aysha Rajeev - Substantial contributions to conception and design, Acquisition of data, Analysis and interpretation of data, Drafting the article, Revising it critically for important intellectual content, Final approval of the version to be published

James Henry - Acquisition of data, Analysis and interpretation of data, Drafting the article, Revising it critically for important intellectual content, Final approval of the version to be published

Nanjappa Kashyap - Acquisition of data, Analysis and interpretation of data, Drafting the article, Revising it critically for important intellectual content, Final approval of the version to be published

\section{Guarantor}

The corresponding author is the guarantor of submission.

\section{Conflict of Interest}

Authors declare no conflict of interest.

\section{Copyright}

(C) Aysha Rajeev et al. 2013; This article is distributed under the terms of Creative Commons attribution 3.0 License which permits unrestricted use, distribution and reproduction in any means provided the original authors and original publisher are properly credited. (Please see www.ijcasereportsandimages.com/copyright-policy.php for more information.)

\section{REFERENCES}

1. Schajowicz F, Clavel Sainz M, Slullitel JA. Juxtaarticular bone cysts (intra-osseous ganglia): a clinicopathological study of eighty-eight cases. J Bone Joint Surg Br 1979;61(1):107-6.

2. Fisk GR. Bone concavity caused by a ganglion. J Bone Joint Surg Br 1949 May;31B(2):220.

3. Feldman F, Johnston A. Intraosseous ganglion. Am J Roentgenol Radium 1973;118(2):328-43.

4. Hicks JD. Synovial cysts in bone. Australian \& New Zealand J Surg 1956;26(2):138-43.

5. DeOrsay RH, Mecray PM, Ferguson LK. Pathology and treatment of Ganglions. Am J Surg 1937;36:3139.

6. Carp L, Stout AP. A study of ganglion with special reference to treatment. Surg Gynecol Obstet 1928;47:460.

7. Valls R, Melloni P, Darnell A, Munoz J, Canalties J. Diagnostic imaging of periosteal ganglion. Eur Radiol 1997;7(1):70-2.

8. Resnick D, Niwayama G. Diagnosis of bone and joint disorders. 2nd ed. Philadelphia: WB Saunders; 1988:1379-82. 
9. Thaunat $\mathrm{M}$, Chambat $\mathrm{P}$. Pretibial ganglion-like cyst formation after anterior cruciate ligament reconstruction:a consequence of the incomplete bony integration of the graft? Knee Surg Sports Traumatol Arthrosc 2007;15(5):522-4.

10. Clatworthy MG, Annear P, Bulow JU, Bartlett RJ. Tunnel widening in anterior cruciate ligament reconstruction: a prospective evaluation of hamstring and patella tendon grafts. Knee Surg Sports Traumatol Arthrosc 1999;7(3):138-45.

11. Malhan K, Kumar A, Rees D. Tibial cyst formation after anterior cruciate ligament reconstruction using a new bioabsorbable screw. Knee 2002;9(1):73-5.
12. Benedetto KP, Fellinger M, Lim TE, Passler JM, Schoen JL, Willems WJ. A new bioabsorbable interference screw: Preliminary results of a prospective, multicentre, randomised clinical trial. Arthroscopy 2000;16(1):41-8.

13. Feldmann DD, Fanelli GC. Development of a synovial cyst following anterior cruciate ligament reconstruction. Arthroscopy 2001;17(2):200-2.

14. Tsuda E, Ishibashi Y, Tazawa K, Sato H, Kusumi T, Toh S. Pretibial cyst formation after anterior cruciate ligament reconstruction with a hamstring tendon autograft. Arthroscopy 2006;22(6):691.e1-6.
Access full text article on other devices

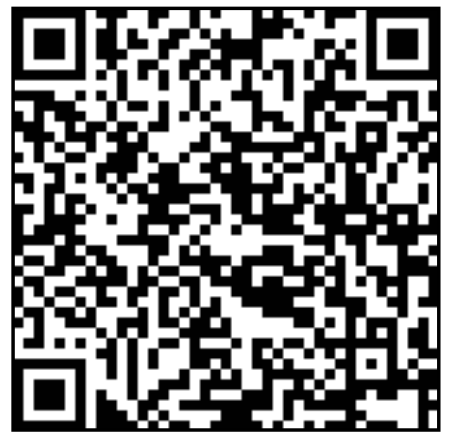

Access PDF of article on other devices

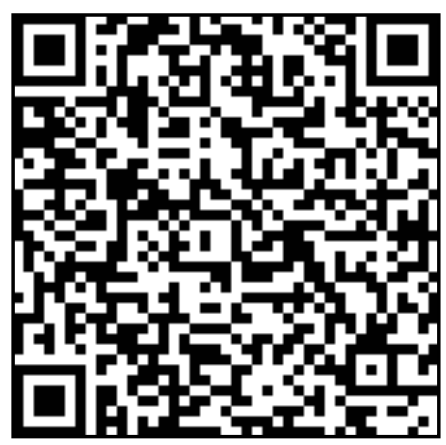

